\title{
SOBRE TRADUÇÃO E ATIVISMO INTELECTUAL ${ }^{12}$
}

\section{RESUMO}

Esta é uma tradução do prefácio escrito por Patricia Hill Collins para a obra Feminist Translation Studies: Local and Transnational Perspectives (2017). A partir de vivências pessoais e de sua trajetória acadêmica e intelectual, Collins expõe sua perspectiva sobre as relações entre tradução e feminismo. Desse modo sua argumentação é dividida em dois momentos: no primeiro, a pessoa da tradutora como uma mediadora entre línguas, pensamentos, culturas e pessoas é focalizada; e, no segundo, o foco recai sobre como a interpretação do pensamento de uma dada comunidade de mulheres pode ser entendida igualmente como um ato de tradução. Para a autora, a tradução dentro desses dois pontos de vista é uma prática ativista e uma ação de confiança naquela que traduz.

Palavras-chave: ativismo, feminismo negro, tradução, mediadora, confiança.

\begin{abstract}
This is a translation of the preface written by Patricia Hill Collins for the book Feminist Translation Studies: Local and Transnational Perspectives (2017). Both from personal experiences and from her academic and intellectual trajectory, Collins exposes her perspective on the relations between translation and feminism. Accordingly, her exposition is divided into two moments: firstly, the person of the translator as a broker for languages, thoughts, cultures and people is focused; and secondly, the focus lies on the interpretation as an act of translation. According to Collins, inside these two points of view, translation is perceived as an activist praxis and an action of trust in the person who translates.
\end{abstract}

Key-words: activism, Black feminism, translation, broker, trust.

\footnotetext{
1 Texto originalmente publicado com o título de "On Translation and Intellectual Activism" em CASTRO, Olga; ERGUN, Emek (Orgs.). Feminist Translation Studies: Local and Transnational Perspectives. Nova York/Londres: Routledge, 2017, p. xii-xvi. Permissão de tradução adquiridos pelos tradutores da Routledge/Taylor and Francis Group LLC Books. Tradução de Cibele de Guadalupe Sousa Araújo, Dennys Silva-Reis e Luciana de Mesquita Silva.

2 Agradecemos à professora Patrícia Collins e à professora Olga Castro pela gentileza e presteza demonstrada na negociação dos direitos autorais da presente tradução brasileira, e também ao professor Marcos Bagno pelo auxílio na solução de alguns questionamentos.
}

\section{Patricia Hill Collins}

Socióloga negra, estadunidense e feminista. Leciona atualmente na Universidade de Maryland. É reconhecida internacionalmente por discutir questões relativas a raça, gênero, classe, representação e feminismo na comunidade afro-americana Algumas de suas principais obras publicadas são: Black Feminist Thought: Knowledge, Consciousness and the Politics of Empowerment (2000), From Black Power to Hip Hop: Racism, Nationalism, and Feminism (2006) e On Intellectual Activism (2002). 
Os diálogos colaborativos que são necessários para a teoria e a práxis feministas raramente ocorrem entre iguais. Como eu gostaria de ser fluente em todas as línguas, estilos comunicacionais e culturas do mundo que me habilitassem a me comunicar com qualquer um/a. Como eu gostaria de ter as habilidades para falar com todo mundo e entendê-los/as da forma como gostariam de ser entendidos/as. Mas eu não sou. Nenhum/a de nós é, então, consequentemente, dependemos de outros/as para traduzirem para nós. Ainda assim, como nossos esforços para entender os/as outros/ as e para nos fazer entendidos/as ocorrem em um mundo caracterizado por relações hierárquicas de poder, por mais que desejássemos que fosse o contrário, há limites em relação ao que cada um/a de nós pode ver e dizer a partir de nossos lugares sociais específicos.

Sinto-me honrada por escrever um prefácio para este livro, porque sua ênfase no feminismo, na tradução e no poder ressoa em duas linhas de meu trabalho. Primeiro, a tradução é central para a práxis feminista. Indivíduos que servem como tradutores/as não apenas interpretam os significados variantes através de cenários sociais, políticos e intelectuais diferentes: eles/as criam novo conhecimento em espaços fronteiriços. $\mathrm{O}$ ato da tradução é visível; por exemplo, a menina de nove anos de idade que traduz suas perguntas para a mãe e vice-versa, porque ela é o elo bilíngue entre o inglês falado na escola e o espanhol falado em casa ${ }^{3}$. Ainda assim, a menina de nove anos de idade faz mais do que traduções literais, palavra por palavra. Como ela pondera e antecipa as necessidades tanto de sua mãe quanto de sua professora, nos dois lados do intercâmbio, ela cria novos entendimentos e possibilidades políticas.

Segundo, este livro tem uma importância especial no meu entendimento de ativismo intelectual. Possuir o poder de uma língua, de uma cultura, de um estilo de comunicação é a marca de poder por si só, tanto dentro de nossas comunidades intelectuais específicas quanto para além delas. Como eu vejo meu trabalho intelectual tanto falando a verdade para os poderosos quanto falando a verdade para o povo, a tradução tem sido importante para o meu ativismo intelectual. Ser capaz de me mover entre diversas comunidades interpretativas, que, por si sós, são situadas politicamente, tomar decisões estratégicas sobre o que se traduz, se se deve realmente traduzir e sobre como as coisas podem ser traduzidas tem sido essencial para o meu trabalho.

Esse foco duplo nas políticas de tradução dentro de hierarquias sociais específicas e as políticas de interpretação que a tradução engendra na criação de um novo conhecimento recai no coração dos estudos de tradução feminista assim como daqueles de qualquer projeto progressista. Dentro das políticas de um mundo em processo de decolonização, a tradução é a ferramenta que catalisa o novo conhecimento que possivelmente fundamenta uma nova práxis política. Portanto, quando se trata

3 Nota dos tradutores: Nesse exemplo, Collins faz referência ao contexto estadunidense de mulheres hispânicas que imigraram para os Estados Unidos possuindo pouco, ou nenhum, domínio do idioma inglês. Já suas filhas e filhos, nascidos no país, são falantes bilíngues, tendo o inglês como língua materna, utilizada em contextos formais como a escola, e o espanhol como língua de herança, utilizada principalmente no contexto familiar. Tais crianças acabam atuando como intérpretes, mediadoras entre os dois contextos: o formal e o familiar. 
de ativismo intelectual, aperfeiçoar habilidades de tradução constitui-se tanto como um desafio intelectual importante quanto como uma necessidade política.

\section{Tradução e práxis feminista}

Em 1994, fui à Europa pela primeira vez para apresentar um trabalho intitulado "Is the Personal Political Enough? African American Women and Feminist Praxis" (1996) [“O pessoalé político o suficiente? Mulheres afro-americanas e práxisfeminista”] na conferência "Racisms and Feminisms: An International Conference" ["Racismos e feminismos: uma conferência internacional”] realizada em Viena. Percebendo que os/as participantes da conferência não falavam uma língua em comum, os/as organizadores/as providenciaram traduções para os trabalhos preparados para e/ou apresentados na conferência que estava ocorrendo. Traduzir o texto escrito de uma comunidade interpretativa para o texto oral ou escrito de uma outra comunidade constituiu-se como um primeiro passo importante para possibilitar que as ideias viajassem. Como a conferência foi encarregada de desenvolver uma agenda feminista para levar à Conferência sobre Racismo das Nações Unidas, nós precisávamos ser capazes de falar um/a com o/a outro/a. Como essa era minha primeira conferência internacional, fiquei estarrecida com o número de pessoas que eu não entendia, ou que não conseguiam me entender. Nós falávamos tantas línguas diferentes que tínhamos dificuldade em falar diretamente uns/umas com os/as outros/as, em conversas abertas e relaxadas. Acima de tudo, eu vi bem claramente como os/as tradutores/as também serviam como mediadores/as de poder para o modo como as ideias formais da conferência se desdobrariam. Eles/as faziam traduções literais dos trabalhos assim como traduziam os estilos comunicacionais e critérios epistemológicos que os/ as participantes da conferência traziam consigo.

Mais tarde, naquele mesmo dia, um jantarzinho informal perto do local da conferência com outros/as três participantes trouxe a importância da tradução para seu mais alto relevo. Um/a de meus/minhas companheiros/as de jantar era uma mulher muçulmana da Bósnia que pediu asilo em Viena para escapar da guerra na Iugoslávia. Ela falava bósnio e um pouco de alemão, mas como ninguém na mesa falava bósnio, ela se apoiava em seu alemão. Um/a segundo/a participante do jantar falava apenas alemão fluente. Como eu falava apenas inglês, não podia me comunicar com nenhum/a deles/as, nem eles/as comigo. Nossa última companheira de jantar falava tanto alemão quanto inglês, e três outras línguas que descobri depois, nenhuma das quais era bósnio. Consequentemente, ela se tornou uma tradutora não oficial para nós três porque ela era a única pessoa na mesa que conseguiu ter uma conversa com cada pessoa na mesa. Até hoje, eu permaneço grata e impressionada pela habilidade e autorreflexividade de nossa companheira de jantar multilíngue. Como ela podia falar com todo mundo na mesa, ela tinha o melhor acesso à conversa significativa. Mas como ela também servia como a tradutora não oficial para a mesa, ela não podia 
simplesmente dizer a primeira coisa que vinha a sua cabeça e esperar para que outra pessoa traduzisse. Em vez disso, ela tinha que refletir sobre o que outras pessoas diziam, sobre seus próprios pensamentos e suas interpretações dos significados que todos/as nós queríamos transmitir.

Que lições podem ser tiradas para o feminismo a partir da organização formal da conferência assim como dos trabalhos informais no jantar? Primeiro, tanto a conferência quanto o jantar destacaram a importância dos/as tradutores/as como mediadores/as de poder dentro das fronteiras linguísticas e culturais que organizam as relações de poder. Consequentemente, em uma situação de desigualdade social marcada por diferentes valorações atribuídas às línguas, tradutores/as sempre serão mediadores/as de poder. A pergunta é: de que tipo? Eu desconfio que presenciei muitas situações em que tradutores/as de outras línguas, por exemplo, aprendendo o jargão acadêmico que permanece sendo o preço de entrada nas disciplinas, possam ter compartilhado comigo apenas aquelas ideias que pensaram que pudessem me interessar, e/ou ser valiosas para mim, ou, mais frequentemente, servir aos seus interesses. Mais ameaçador do que isso é o fato de tais tradutores/as poderem ter omitido informações que poderiam ter me beneficiado. Nesses cenários, tradutores/ as servem como mediadores/as de poder tanto dos interesses de grupos dominantes ou oportunamente de seus próprios interesses - guardas de fronteira que decidem quais ideias merecem ser traduzidas nos dois lados do poder. Em contrapartida, experiências dialógicas em cenários feministas onde pessoas progressistas se esforçam para entender o ponto de vista umas das outras para além de diferenças de nacionalidade, idade, sexualidade, classe e/ou raça podem se assemelhar àquelas daquele jantar. Para mim, nossa colega multilíngue interpretou e exercitou seu papel como uma mediadora de poder dentro do contexto do ativismo intelectual. Ela viu a tradução como sendo essencial para o tipo de diálogos e colaborações intelectuais requisitados pelo conhecimento e pela práxis feministas.

Segundo, tradutores/as com histórias diferentes de ativismo intelectual podem se deparar com o confronto de um/a com o/a outro/a no mesmo espaço interpretativo. Apesar de a tradução parecer ser uma simples reiteração de um conjunto de verdades na língua do/a outro/a, o processo é profundamente enredado em relações de poder desiguais. Não é uma simples transferência de uma língua para outra. Ao contrário, a natureza da tradução reflete o suposto valor das ideias nos diferentes lados de uma divisão cultural, na qual aqueles/as em cada um dos lados não têm outro modo de ter engajamento dialógico (eles/as poderiam se comunicar certamente, talvez violentamente e sem compreensão mútua) a não ser por meio de mediadores/as de língua. Tradutores/as experientes que estão comprometidos/as com o ativismo intelectual frequentemente se vêem confrontando mediadores/as de poder que trabalham para manter relações de poder e/ou seu próprio carreirismo. Para além de simples oposição à desigualdade, tradutores/as progressistas frequentemente usam seu lugar social como mediadores/as de poder para construir espaços subversivos e transgressivos entre pessoas que compartilham interesses e línguas diferentes. 
Tradutores/as que reconhecem as complexidades do poder e a importância de o processo de tradução atuar eticamente naquele espaço.

Terceiro, a tradução tem implicações epistemológicas importantes para o tipo de conhecimento feminista que emerge da práxis feminista. O espaço da tradução não é um espaço vazio, uma função que pode ser ocupada por qualquer um/a, onde verdades são construídas pelo mapeamento linear de um conjunto de ideias dentro daquelas de uma outra. Em vez disso, porque a tradução facilita a comunicação, espaços de tradução possibilitam que as ideias ressaltem umas às outras. Ainda assim, compartilhar ideias via tradução requer confiança. No jantar, por exemplo, como eu não falava nem alemão nem bósnio, não tinha como saber se qualquer um/a na mesa estava falando a verdade, incluindo a tradutora da mesa. Por mais que eu confiasse na minha companheira de jantar, não havia outro modo de verificar os significados sociais compartilhados a não ser adicionar mais pessoas à conversa. $\mathrm{E}$ esse é exatamente o ponto de construção do conhecimento dialógico que é necessário a relações de decolonização e facilitado por tradutores/as que abraçam o ativismo intelectual. Nesse caso, como o jantar surgiu de um evento feminista mais amplo que era dedicado ao antirracismo, eu confiei em meus/minhas companheiros/as. Para mim, nossa mesa de jantar constituiu-se como uma efêmera zona de fronteira para a escuta ativa e não simplesmente falar para ou por cima um/a do/a outro/a. Havia um elemento de confiança entre pessoas desconhecidas, com um diálogo subsequente que felizmente energizou cada um/a de nós. Espaços de tradução são zonas de fronteira epistemológica, onde o conhecimento é construído via confiança.

\section{As políticas de interpretação: tradução e estudos acadêmicos feministas}

Eu estou atualmente envolvida em vários projetos que me demandam refletir retrospectivamente sobre Black Feminist Thought4 [Pensamento feminista negro], um esforço interessante que requer uma tradução temporal de outrora para agora. Mesmo que eu não tenha tido acesso aos estudos de tradução feminista quando escrevi Black Feminist Thought (1990), o que me impressiona é quão importante a tradução foi para aquele projeto. Eu enfrentei um desafio difícil ao elaborar esse livro - como eu poderia escrever um livro sobre a produção intelectual das mulheres afroamericanas que fosse aceito pelo público acadêmico que tinha excluído e depreciado as mulheres afro-americanas por um longo período de tempo? Por outro lado, como eu poderia escrever um livro que falasse diretamente às mulheres afro-americanas que elas achassem confiável, ainda assim evitando o risco de ser desconsiderado pelo público acadêmico (que controlava os recursos de publicação)?

4 Black Feminist Thought: Knowledge, Consciousness and the Politics of Empowerment foi publicado originalmente em 1990, e ainda não conta com tradução completa e/ou oficial no Brasil. Sua publicação em língua portuguesa está prevista para o ano de 2019, pela editora Boitempo. 
Black Feminist Thought exigiu que eu aguçasse minhas habilidades de tradução, sobretudo porque eu estava escrevendo em uma zona de fronteira que percorria comunidades linguísticas, culturais e epistemológicas que não eram iguais. As mulheres afro-americanas tinham claramente sido usadas como dados para agendas acadêmicas, úteis apenas quando serviam aos tropos dominantes. Como análises por e sobre mulheres negras naquele tempo eram tão novas e eu era uma acadêmica desconhecida, eu sabia que meu livro tinha poucas chances de ser publicado a não ser que passasse pelo escrutínio acadêmico. Ainda assim, o escrutínio acadêmico era e continua sendo uma relação de poder que convida certos materiais a viajar para dentro das arenas acadêmicas enquanto considera outros materiais não merecedores de investigação. Eu também tinha que encontrar modos de ver se os argumentos que eu desenvolvia alinhavam-se com os significados que as mulheres afro-americanas expressariam sobre suas vidas.

Eu enfrentei vários desafios ao escrever Black Feminist Thought, um de inteligibilidade, ou de construir ideias que pudessem viajar e fazer sentido nos dois âmbitos; e um de clareza, ou de garantir que eu nem compreendesse mal nem representasse mal as ideias em comunidades interpretativas que raramente comunicavam-se umas com as outras como iguais; e um de legitimação, mais precisamente, garantir que meus argumentos seriam convincentes dentro de diferentes padrões de avaliação. Compreendendo meu papel como uma mediadora de poder nesse contexto, tive que encontrar modos para me comunicar com diversas comunidades interpretativas sem reinstalar as hierarquias de poder que subordinavam uma à outra. Para solucionar esse dilema, eu me engajei em uma metodologia dialógica ou uma maneira de ler as ideias de diversas comunidades interpretativas. Eu via a escrita de meu livro como uma forma de falar diversas línguas, variações do inglês que eram usadas e validadas por diversas comunidades interpretativas. Quando olho para trás, vejo que me engajei em uma estratégia dupla de falar a verdade para os/as poderosos/as por meio da referência ateorias sociais reconhecidas e pesquisa empírica dentro de Black Feminist Thought, assim como de falar a verdade para o povo, que eram os sujeitos de meu manuscrito.

Falar a verdade para os/as poderosos/as era muito perigoso. Como uma recém acadêmica, eu era bastante cuidadosa sobre como eu compartilhava meu trabalho, esperando até eu ganhar estabilidade antes de procurar um contrato editorial. Eu achei que estivesse preparada para a crítica de meus/minhas colegas acadêmicos, mas percebi com o tempo que muitos de meus/minhas colegas mais velhos/as possuíam a base de conhecimento e o conjunto de habilidades para compreender a complexidade de meu projeto. Por exemplo, após eu terminar uma apresentação de Black Feminist Thought em uma conferência acadêmica feminista, uma participante levantou a mão, recitou uma lista de obras de feministas brancas proeminentes e perguntou por que eu não as tinha citado. Ela parecia insinuar que meu livro melhoraria se eu incorporasse mais teoria feminista. Em resposta, assinalei que eu certamente estava familiarizada com as obras canonizadas, mas que tinha deliberadamente escolhido não citá-las. As teóricas feministas brancas que ela citou não precisavam de mais 
valorização vinda de mim - elas já tinham pessoas como ela para traduzi-las e defender suas causas. Em vez disso, eu queria convidar para a conversa mais pessoas no espaço de fronteira, nesse caso, as mulheres afro-americanas que tinham sido excluídas pelas mesmas táticas que minha crítica usou naquele mesmo momento.

Falar a verdade para o povo acabou sendo a parte mais jubilosa desse projeto. Minha maior preocupação era que as mulheres negras que eram os sujeitos de meu livro não se sentissem como objetos do conhecimento quando elas lessem Black Feminist Thought. Eu também usei minha docência para "traduzir" teorias antirracistas, feministas e outras teorias sociais progressistas para meus/minhas alunas, muitos/as dos/as quais estavam com sede de novas ideias. Eu coloquei as ideias de uma gama de intelectuais afro-americanos/as, artistas e críticos/as culturais em diálogo com as de meus/minhas alunos/as, "traduzindo", assim, para eles/as e a partir deles/as as ideias mais robustas. Ao preparar o manuscrito final, compartilhei vários capítulos com graduandas afro-americanas e as questionei sobre suas reações ao manuscrito. As ideias em Black Feminist Thought "soavam verdadeiras" para elas? Elas conseguiam pensar em exemplos de suas próprias experiências que ilustrassem e/ou contradissessem as ideias principais do livro? Quão efetivamente as explicações e interpretações que eu ofereci, muitas das quais foram tiradas de teorias sociais acadêmicas, falavam sobre suas realidades vividas? O material que elas acharam irrelevante simplesmente não se traduzia para elas, não importando o quanto os círculos acadêmicos o retratassem como verdade. Paralelamente, minhas alunas questionavam-me rotineiramente sobre os temas que não apareciam no livro, pedindo-me para escrever mais sobre eles.

Black Feminist Thought está escrito em diversos registros, um voltado para o público acadêmico e o outro visando à leitura geral, ainda que heterogênea, das mulheres afro-americanas. Meu trabalho como acadêmica recai no aperfeiçoamento da arte da tradução de perspectivas tão diversas no mundo para além dessas diferenças de cultura, de experiência, mas, sobretudo, de poder.

$\mathrm{O}$ mundo não nos pertence para que o agarremos e o entendamos como transparente, terminado e pronto para levar. Dentro de uma conjuntura ocidental, o desejo por conhecer catalisou a crença de que a ciência pode revelar tudo que é conhecível se seguirmos as regras e que o desconhecido tipicamente não merece ser conhecido. Nesse contexto, é difícil aceitar um processo de tradução perpétua que revele camadas de significado que nós nunca poderemos conhecer enquanto indivíduos. Ainda assim, não há um modo de conhecer nosso mundo sem cruzar fronteiras linguísticas, culturais e epistemológicas, de assumir riscos tanto em conversas quanto dentro de nossa produção intelectual. Nós nunca podemos requerer ou vivenciar as experiências de outras pessoas, ou mesmo os sentidos que as pessoas fazem delas, sem violentar suas realidades. Nesse contexto, trabalhar dialogicamente e aperfeiçoar habilidades de tradução é um ato de confiança - em nossas próprias 
habilidades e naquelas de outros em acertar, ou ao menos chegar o mais perto disso quanto puderem.

\section{Referências bibliográficas}

COLLINS, Patrícia, H. "Is the Personal Political Enough? African-American Women and Feminist Praxis." Pp. 67-91 In: Rassismen \& Feminismen. FUCHS, Brigitte; HABINGER, Gabriele (orgs.). Vienna: Promedia (in German), 1996.

Black Feminist Thought: Knowledge, Consciousness and the Politics of Empowerment. 2ed. New York/London: Routledge, 2000. 